\title{
MATHEMATICAL MODEL OF THE JET ENGINE FUEL SYSTEM
}

\author{
Marek Klimko ${ }^{1, \mathrm{a}}$ \\ ${ }^{I}$ University of West Bohemia, Department of Power System Engineering, Univerzitni 8, 30614 Pilsen, Czech Republic
}

\begin{abstract}
The paper discusses the design of a simplified mathematical model of the jet (turbo-compressor) engine fuel system. The solution will be based on the regulation law, where the control parameter is a fuel mass flow rate and the regulated parameter is the rotational speed. A differential equation of the jet engine and also differential equations of other fuel system components (fuel pump, throttle valve, pressure regulator) will be described, with respect to advanced predetermined simplifications.
\end{abstract}

\section{Introduction}

The management target is to evaluate and elaborate information about the controlled process; in the given case it is the turbo-compressor engine operation, whereas the particular devices influencing its operation are controlled. The special case of the controlling is regulation, during which the pre-selected engine parameters are kept (regulated) in the pre-set values, corresponding the particular engine operation mode.

The objective of the jet engine study, as a regulated system, is to clarify its dynamic properties determining the engine response to external error variables (such as a change in pressure and air temperature at the compressor inlet, the activation of anti-surge device of compressor etc.), and to define the effect of the regulating variables (e.g. fuel mass supply effect, a change in the outlet nozzle geometry etc.).

Furthermore, we will deal in this paper with a fuel mass supply effect, whereas the rotational engine speed is the regulated variable. Therefore, we are talking about the regulation law:

$$
n=f\left(Q_{p}\right)
$$

\section{The jet engine as a controlled object}

The aim of the automatic control is to remove the controlled variable deviations from the desired values arising from different causes, so it is advisable to determine the dynamic properties near the steady mode of the engine.

By the investigating dynamic properties, the static characteristics are derived. Differential equation of the rotor is:

$$
\frac{\pi \cdot J}{30} \cdot \frac{d n}{d t}=M_{T}-M_{K} .
$$

where:

$J$ moment of inertia, $\mathrm{m}^{4}$

$M_{T}$ turbine torque, $\mathrm{N} \cdot \mathrm{m}$

$M_{K}$ compressor torque, $\mathrm{N} \cdot \mathrm{m}$

Torque of the turbine and compressor are under constant conditions functions of rotational speed and quantity of the fuel flow supply.

$$
\begin{aligned}
& M_{T}=f\left(n, Q_{p}\right), \\
& M_{K}=f\left(n, Q_{p}\right) .
\end{aligned}
$$

Using linearization and mathematical modifications we get the differential equation of the jet engine with a fixed geometry (detail of the calculation procedure can be found in [1]):

$$
\begin{gathered}
\frac{\pi \cdot J}{30 \cdot\left(\frac{\partial M_{K}}{\partial n}-\frac{\partial M_{T}}{\partial n}\right)_{0}} \cdot \frac{d \bar{n}}{d t}+\bar{n}= \\
=\frac{\left(\frac{\partial M_{T}}{\partial Q_{p}}-\frac{\partial M_{K}}{\partial Q_{p}}\right)_{0}}{\left(\frac{\partial M_{K}}{\partial n}-\frac{\partial M_{T}}{\partial n}\right)_{0}} \cdot \frac{Q_{p z}}{n_{z}} \cdot \bar{Q}_{p} \\
T_{p} \cdot \frac{d \bar{n}}{d t}+\bar{n}=k_{p} \cdot \bar{Q}_{p} .
\end{gathered}
$$

$T_{p}$ is a time constant, which determines the speed of the transition process, and which does not depend on the size of the error (within the allowable limits of an accepted linearization).

Gain coefficient $k_{p}$ characterizes the sensitivity of the jet engine to change the fuel mass flow. 


\section{The jet engine fuel system}

The jet engine fuel system can be illustrated by a simplified block scheme (Figure 1).

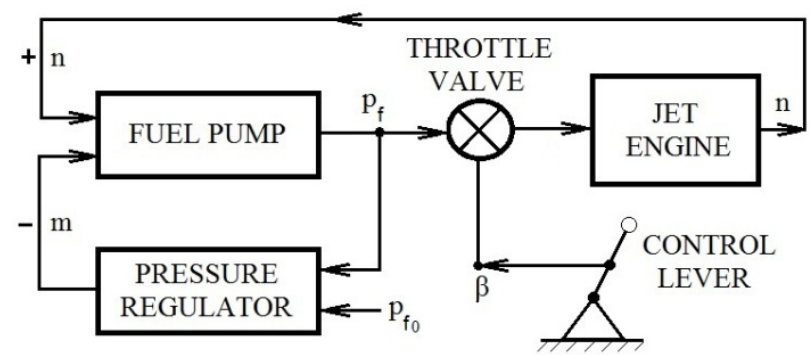

Fig. 1. Schematic representation of the jet engine fuel system

The constant fuel mass flow into the engine, with the constant position of the control lever, can be provided by keeping a constant fuel pressure before the throttle valve $\left(p_{f}=\right.$ const. $)$, or by keeping a constant fuel pressure drop at the throttle valve.

The regulator indicated the Figure 1. balances out the real pressure $p_{f}$ with the aligned value $p_{f 0}$. When $p_{f} \neq p_{f 0}$, it influences the regulated unit of the fuel pump, so that the condition $p_{f}=p_{f 0}$ is fulfilled. For example, when $\left(p_{f}-p_{f 0}\right)>0$, the regulator causes a change of the powerful regulated unit $(-\Delta m)$ and the fuel mass flow decreases to the original value. The fuel flow into the engine is determined by the position of the throttle valve control lever $\beta$.

To make a dynamic description of the whole system, we need to know differential equations of individual components. The dynamic description of the jet engine is characterized by the equation (6), so remains to determine differential equations of the fuel pump, throttle valve, and fuel pressure regulator.

\subsection{Differential equation of fuel pump}

The block scheme of the fuel pump with indicated input and output parameters is illustrated in Figure 2.

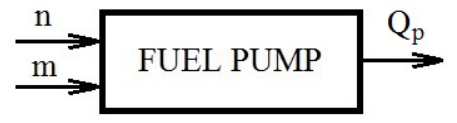

Fig. 2. Block scheme of fuel pump with input and output parameters

Considering that the characteristics of the fuel pump and the fuel pipe do not change, the provided fuel flow through the fuel pump depends only on the change of the engine speed and the position of the regulated unit, when $Q_{p}=f(n, m)$. A partial influence of the change of one input parameter on the change of the supplied fuel flow through the fuel pump is indicated by the fuel pump static characteristics.

Fuel is basically incompressible fluid and a deformation of the fuel pump and fuel pipes are very small in the operation, therefore we can examine the fuel pump as an inertial transmission unit. Its equation in deviations can be written in the following form:

$$
\begin{gathered}
\Delta \mathrm{Q}_{\mathrm{p}}=\left(\frac{\partial \mathrm{Q}_{\mathrm{p}}}{\partial \mathrm{n}}\right) \cdot \Delta \mathrm{n}+\left(\frac{\partial \mathrm{Q}_{\mathrm{p}}}{\partial \mathrm{m}}\right) \cdot \Delta \mathrm{m} \\
\bar{Q}_{p}=k_{n} \cdot \bar{n}+k_{m} \cdot \bar{m}
\end{gathered}
$$

where:

$\bar{m}=\frac{\Delta m}{m_{z}}-$ relative change of the regulated unit position,

$k_{n}=\left(\frac{\partial Q_{p}}{\partial n}\right)_{0} \cdot \frac{n_{z}}{Q_{p z}}-$ fuel pump gain coefficient depending on the change of rotational speed,

$k_{m}=\left(\frac{\partial Q_{p}}{\partial m}\right)_{0} \cdot \frac{m_{z}}{Q_{p z}}-$ fuel pump gain coefficient depending on the change of the regulated unit position.

\subsection{Differential equation of the throttle valve}

When deriving the throttle valve equation we will proceed just like when deriving the fuel pump equation. The input parameters are the position of the throttle valve control lever $\beta$ and the fuel pressure before the throttle valve $p_{f}$.

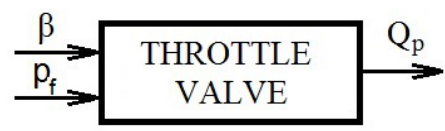

Fig. 3. Block scheme of throttle valve with input and output parameters

By linearization of flow characteristics, when using deviations of parameters, we can write the throttle valve equation in this form:

$$
\bar{Q}_{p}=k_{\beta} \cdot \bar{\beta}+k_{p f} \cdot \bar{p}_{f}
$$

where:

$k_{\beta}=\left(\frac{\partial Q_{p}}{\partial \beta}\right)_{0} \cdot \frac{\beta_{z}}{Q_{p z}}-$ throttle valve gain coefficient depending on the change of the control lever position $k_{p f}=\left(\frac{\partial Q_{p}}{\partial p_{f}}\right)_{0} \cdot \frac{p_{f z}}{Q_{p z}}-$ throttle valve gain coefficient depending on the change of the fuel pressure before it $\bar{p}_{f}=\frac{\Delta p_{f}}{p_{f z}}-$ relative change of the fuel pressure

\subsection{Differential equation of the direct fuel pressure regulator}

A sensor and a control unit are the only construction components, on which the hydraulic power from pressure $p_{f}$ a lines with the spring power.

An equation of the direct fuel pressure regulator before the throttle valve, when ignoring inertial and friction forces of the overflow valve, can be written in a simple form:

$$
\bar{m}=-k_{r} \cdot \bar{p}_{f}
$$


The minus sign states the fact that a negative deviation of the regulation unit corresponds to any positive change of the fuel pressure before the throttle valve - lifting up the overflow valve and consequently a drop of fuel mass flow into the engine, in comparison with its value when $m=$ const.

$$
k_{r}=-\left(\frac{d m}{d p_{f}}\right)_{0} \cdot \frac{p_{f z}}{m_{z}} .
$$

The relation (11) defines the value of the direct regulator gain coefficient depending on the change of the fuel pressure before the throttle valve.

\section{Differential equation of the system}

The control system consists of a jet engine, a fuel pump, a throttle valve, and a direct fuel pressure regulator. We already know the differential equation of all the components of the system (6), (8), (9), (10).

$$
\begin{gathered}
T_{p} \cdot \frac{d \bar{n}}{d t}+\bar{n}=k_{p} \cdot \bar{Q}_{p}, \\
\bar{Q}_{p}=k_{n} \cdot \bar{n}+k_{m} \cdot \bar{m}, \\
\bar{Q}_{p}=k_{\beta} \cdot \bar{\beta}+k_{p f} \cdot \bar{p}_{f}, \\
\bar{m}=-k_{r} \cdot \bar{p}_{f} .
\end{gathered}
$$

We will examine the system focusing on the determination of such an equation, indicating the relation between the input and output variables, as illustrated in Figure 4.

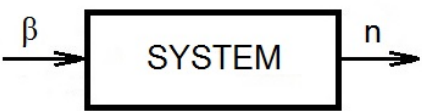

Fig. 4. Block scheme of the jet engine fuel system

According to the Figure 4, it is apparent that we are looking for an equation of motion, which will define the relation between the engine speed and the position of the throttle valve control lever.

$\bar{m}$ from the equation (8) is substituted by the equation 10), consequently, from the relation (9), we will express the parameter $p_{f}$, which we will incorporate into the modified equation (10).

$$
\begin{aligned}
& \bar{Q}_{p}=k_{n} \cdot \bar{n}+k_{m}\left[-k_{r}\left(\bar{Q}_{p}-k_{\beta} \cdot \bar{\beta}\right) \cdot \frac{1}{k_{p f}}\right], \\
& \bar{Q}_{p}=k_{n} \cdot \bar{n}-\bar{Q}_{p} \cdot \frac{k_{m} \cdot k_{r}}{k_{p f}}+\bar{\beta} \frac{k_{\beta} \cdot k_{m} \cdot k_{r}}{k_{p f}}, \\
& \bar{Q}_{p}+\bar{Q}_{p} \cdot \frac{k_{m} \cdot k_{r}}{k_{p f}}=k_{n} \cdot \bar{n}+\bar{\beta} \frac{k_{\beta} \cdot k_{m} \cdot k_{r}}{k_{p f}},
\end{aligned}
$$

$$
\begin{gathered}
\bar{Q}_{p} \cdot\left(1+\frac{k_{n} \cdot k_{r}}{k_{p f}}\right)=k_{n} \cdot \bar{n}+\bar{\beta} \frac{k_{\beta} \cdot k_{m} \cdot k_{r}}{k_{p f}}, \\
\bar{Q}_{p}=\frac{k_{n} \cdot \bar{n}+\bar{\beta} \cdot \frac{k_{\beta} \cdot k_{m} \cdot k_{r}}{k_{p f}}}{1+\frac{k_{m} \cdot k_{r}}{k_{p f}}} .
\end{gathered}
$$

By incorporating the equation (16) into the equation (6) we get:

$$
\begin{gathered}
T_{p} \cdot \frac{d \bar{n}}{d t}+\bar{n}=k_{p} \cdot \frac{k_{n} \cdot \bar{n}+\bar{\beta} \cdot \frac{k_{\beta} \cdot k_{m} \cdot k_{r}}{k_{p f}}}{1+\frac{k_{m} \cdot k_{r}}{k_{p f}}} \\
T_{p} \cdot \frac{d \bar{n}}{d t}+\bar{n}-\frac{k_{p} \cdot k_{n} \cdot k_{p f}}{k_{p f}+k_{m} \cdot k_{r}} \cdot \bar{n}= \\
=\frac{k_{p} \cdot k_{\beta} \cdot k_{m} \cdot k_{r}}{k_{p f}+k_{m} \cdot k_{r}} \cdot \bar{\beta} \\
T_{p} \cdot \frac{d \bar{n}}{d t}+\left(1-\frac{k_{p} \cdot k_{n} \cdot k_{p f}}{k_{p f}+k_{m} \cdot k_{r}}\right) \cdot \bar{n}= \\
=\frac{k_{p} \cdot k_{\beta} \cdot k_{m} \cdot k_{r}}{k_{p f}+k_{m} \cdot k_{r}} \cdot \bar{\beta} .
\end{gathered}
$$

The equation (19) represents the final differential equation of the system "jet engine, fuel pump, throttle valve and fuel pressure direct regulator."

\section{Implementation and results}

The implementation of the differential equation of the whole solved system was run in the program environment Matlab-Simulink ${ }^{\circledR}$.

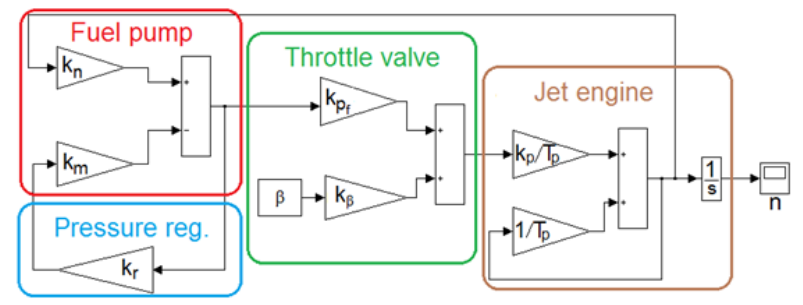

Fig. 5. Implementation of the particular parts of the fuel system, including the jet engine in the program Matlab-Simulink ${ }^{\mathbb{R}}$

The following picture illustrates the process of the relative rotational speed in time of the system "jet engine, fuel pump, throttle valve and fuel pressure regulator" depending on the change of the position of the throttle valve control lever. 


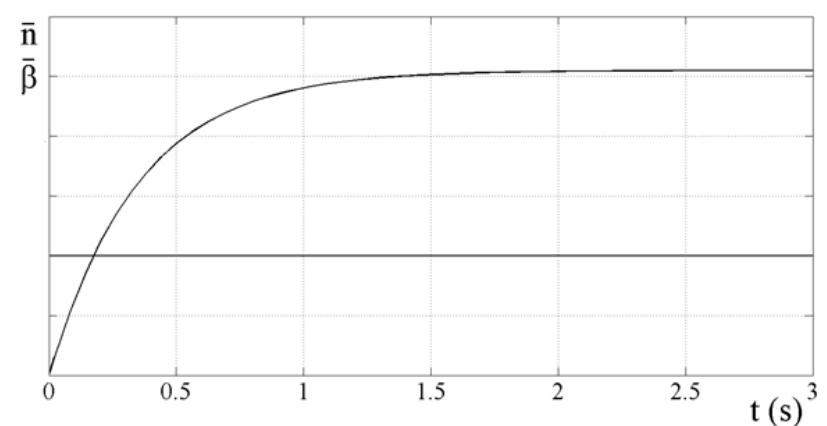

Fig. 6. System response in time to step change $\beta$

By a step open of the throttle valve the fuel flow supply into the engine will increase, which will also increase the engine speed. The important parameter, determining the speed of the transition process stabilization, is the engine time constant $T_{p}$. The change of this constant in the transition process can be observed in the following dependence.

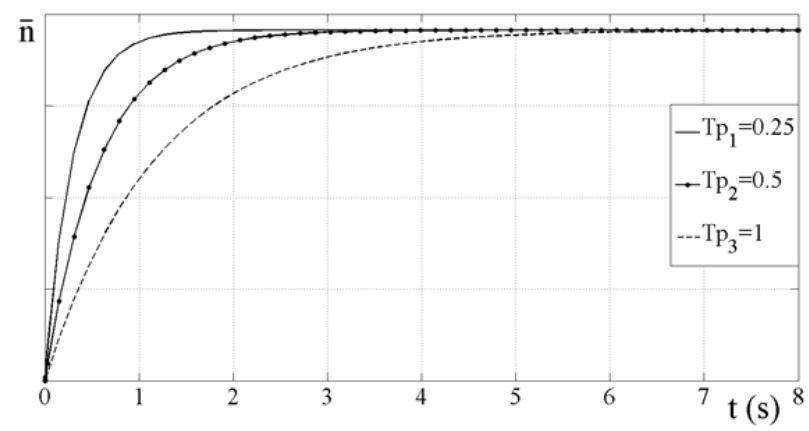

Fig. 7. Impact of time constant on relative speed change process

The second observed parameter is the position of the throttle valve lever $\beta$. As this value increases, the flow cross-section of the throttle valve increases at the same time, which results in the fuel supply increase in the engine, and also the relative rotational speed growth.

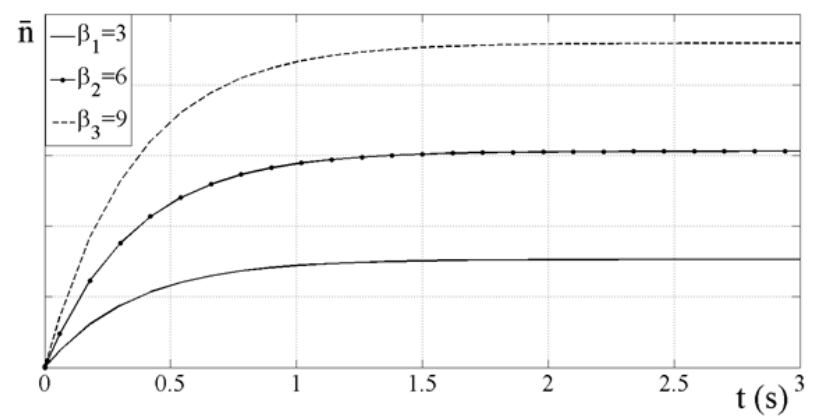

Fig. 8. Impact of the throttle valve lever position change $\beta$

\section{Conclusions}

The simulation of the simplified model of the jet engine fuel system points out at the transition process response of the whole system, in case of changes in some important parameters. The issue of the jet engine as a controlled object is still valid. The advantage of the mathematical model is mainly the fact that the mathematical model enables to predict the system behavior even in case the proposed system has not been physically made yet.

\section{References}

1. M. Klimko, P. Zitek, Controlling the jet engine by fuel injection (QUAERE 2014, Hradec Králové, 2014) ISBN 978-80-87952-04-7

2. M.S. Fadali, Digital Control Engineering (Elsevier Inc., 2009) ISBN 978-0-12-374498-2

3. S. Lyshevski, Engineering and Scientific Computations using MATLAB ${ }^{\circledR}$ (John Wiley \& Sons, Inc., New Jersey, 2003) ISBN 0-471-46200-4

4. P. Noskievič, Modelováni a identifikace systémů (Montanex a.s., 1999) ISBN 80-7225-030-2

5. H. Richter, Advanced Control of Turbofan Engines (Springer Science, Cleveland-USA, 2012). ISBN 978-1-4614-1170-3

6. L. Vítek, E. Heriban, Regulace leteckých lopatkových motori̊ I. (Vojenská akademie Antonína Zápotockého, Praha, 1978)

\section{Acknowledgement}

The presented research is supported by the student project SGS-2014-070 (Increasing the efficiency, reliability and durability of power system devices 3 ). 